\title{
A Miniaturized Ligand Binding Assay for EGFR
}

\author{
Jochen M. Schwenk, ${ }^{1,2}$ Oliver Poetz, ${ }^{1}$ Robert Zeillinger, ${ }^{3}$ and Thomas O. Joos ${ }^{1}$ \\ ${ }^{1}$ NMI Natural and Medical Sciences Institute at the University of Tübingen, Markwiesenstraße 55, 72770 Reutlingen, Germany \\ ${ }^{2}$ Science for Life Laboratory Stockholm, School of Biotechnology, KTH Royal Institute of Technology, P.O. Box 1031, \\ 17121 Solna, Sweden \\ ${ }^{3}$ Molecular Oncology Group, Department of Obstetrics and Gynecology, Medical University of Vienna, \\ Währinger Gürtel 18-20, 5Q, 1090 Vienna, Austria
}

Correspondence should be addressed to Jochen M. Schwenk, jochen.schwenk@scilifelab.se

Received 9 September 2011; Revised 17 January 2012; Accepted 18 January 2012

Academic Editor: Ákos Végvári

Copyright ( 92012 Jochen M. Schwenk et al. This is an open access article distributed under the Creative Commons Attribution License, which permits unrestricted use, distribution, and reproduction in any medium, provided the original work is properly cited.

In order to study receptor abundance and its function in solutions or in homogenates from clinical specimen, methods such as sandwich or radioimmunoassays are most commonly employed. For the determination of epidermal growth factor receptor (EGFR), we describe the development of a miniaturized bead-based ligand binding assay using its ligand EGF as immobilized capture reagent. This assay was used to analyze lysates from cell lines, and the ligand-bound EGFR was detected using an EGFRspecific antibody combined with a fluorescence-based reporter system. In a proof-of concept study with lysates from breast biopsies, the assay allowed to classify breast cancer samples in accordance to clinically the relevant EGFR cut-off level. The study suggests that such a ligand binding receptor assay could become an integral part of protein profiling procedures to provide additional information about receptor functionality in addition to its abundance.

\section{Introduction}

Since their introduction in the 1960s [1], immunoassays based on radiolabeled ligands or antibodies have become well-established technologies in research and clinical chemistry. Today, antibody-based immunoassays have been transferred and applied to various technological platforms such as multiplexed and miniaturized formats used in proteomic experiments $[2,3]$. These multiplexed assay systems now allow analyzing hundreds of proteins in a single affinitybased experiment, but, thus far, radioimmunoassay-like measurements of ligand binding active receptors have not yet been transferred in a miniaturized format.

In the context of a detailed analysis of breast cancer, the quantification of active epithelial growth factor receptor (EGFR) in clinical specimen is a prominent example for the application of a radio-ligand binding assay. The investigation of receptor tyrosine kinases such as the EGFR is of interest, as overexpression of EGFR is correlated with poor prognosis [4], and the expression rates of EGFR and hormone receptors were strongly inverse [5]. EGFR itself is a transmembranespanning protein, with an extracellular ligand binding and a cytoplasmatic tyrosine kinase domain [6], and its main ligand EGF is a polypeptide consisting of 53 amino acids that binds to domain I and III of the extracellular part of the receptor. Upon binding of EGF to EGFR, the receptor undergoes conformational changes [7]. These lead to a downstream activation of the NF- $\kappa \mathrm{B}$ transcription factor pathway to induce antiapoptotic and proliferated genes, which eventually results in cell growth. EGFR plays a key role in the regulation of essential normal cellular processes and in the pathophysiology of hyperproliferated diseases such as many epithelial cancer types like breast, ovarian, lung, colorectal or prostate cancer [8]. EGFR is also known to be activated in a variety of tumors via the promotion of its gene c-erbB1, leading to an overexpression [9] by mutation or ligand binding [10]. EGFR expression may even serve as a decision maker for EGFR-targeted therapies [11], and, recently, the use of specific monoclonal antibodies directed against the phosphorylated and mutant form of 
EGFR (EGFRvIII) was suggested as a valid predictor of response to therapy with cetuximab, an anti-EGFR antibody [12].

To measure the levels of EGFR in tissue samples, sandwich immunoassays can be used [13]. Complementary to these, radio-ligand binding assays (RLB) perform a more classical approach to measure quantities of functional EGFR by employing ${ }^{125}$ I-labeled EGF [14]. This receptor ligand binding assay takes advantage of the strong interaction between the ligand EGF and EGFR, which bind with an affinity of $\leq 12 \mathrm{nM}$ [15].

In the study presented here, we have developed a miniaturized solid-phase-based ligand binding assay as a possible alternative to assays involving radioactive tracers. Instead of using an EGFR specific antibody, we have employed the ligand EGF as a reagent to capture and profile functional EGFR present in the samples. This assay only requires small amounts of sample to determine relative EGFR level in lysates from cell culture material as well as from patient samples. The study reveals that bead-based ligand binding assay offers a complementary system to sandwich immunoassays and radioimmunoassays.

\section{Methods and Material}

2.1. Preparation of Cell Samples. Frozen pellets of the human breast cancer cells BT-20 (ATCC no. HTB-19) were solubilized on ice with $2 \%(\mathrm{v} / \mathrm{v})$ NP-40 (Sigma) in a buffer containing $50 \mathrm{mM}$ Tris (Sigma), $120 \mathrm{mM} \mathrm{NaCl}, 1 \mathrm{mM} \mathrm{CaCl}$, $1 \mathrm{mM} \mathrm{MgCl}_{2}$, and 2\% (v/v) protease inhibitor (Sigma). The cells were sonicated 4 times for $5 \mathrm{~s}$ (Branson Sonifier, Korea) and centrifuged at $13,000 \mathrm{rpm}$ for $5 \mathrm{~min}$. The supernatant was collected for further studies.

2.2. Tissue Samples. Membrane fractions of 46 breast cancer samples with EGFR levels between 0 and $600 \mathrm{fmol}$ EGFR per $\mathrm{mg}$ protein were included in the study (Supplementary Table 1 available online at doi:10.1155/2012/247059). The EGFR level was analyzed by a radio-ligand binding assay [14]. Seventeen samples had an EGFR level $\leq 10 \mathrm{fmol} / \mathrm{mg}$, and 29 samples had EGFR levels of 11-246 fmol/mg. One sample had an EGFR concentration of $600 \mathrm{fmol} / \mathrm{mg}$. All samples had been stored at $-80^{\circ} \mathrm{C}$ for about 10 years.

2.3. Coupling of Beads. Biotinylated EGF (EGF-Biot, Molecular Probes) was coupled to avidin-coated beads (LumAvidin beads, Luminex Corporation). In each coupling reaction, 2.5 $\times 10^{5}$ beads were used. Firstly, beads were washed twice in block-and-storage buffer (BSB) containing $1 \%$ bovine serum albumin (Carl Roth) in phosphate-buffered saline ( $\mathrm{pH}$ 7.4). Washing steps were performed as follows: beads were sedimented at 10,000 g for $2 \mathrm{~min}$, supernatant was removed, and beads were resuspended with $250 \mu \mathrm{L}$ BSB, vortexed, and sonicated. EGF was coupled onto two differently colorcoded bead sets at EGF-Biot concentrations of $1.2 \mu \mathrm{M}$ and $0.3 \mu \mathrm{M}$ over 30 min under permanent shaking in BSB buffer. Beads were washed twice with BSB and stored in BSB buffer containing $0.01 \%$ sodium azide (Merck) at $4^{\circ} \mathrm{C}$ in the dark before use.

2.4. Miniaturized Ligand Binding Assay. Assays were performed in a 96-well microtiter plate with a filter-membrane bottom (Millipore) in BSB under permanent shaking at $650 \mathrm{rpm}$ and $23^{\circ} \mathrm{C}$ in the dark. In each well, $30 \mu \mathrm{L}$ containing EGF-Biot beads (1000 per set) and $30 \mu \mathrm{L}$ of sample were mixed and incubated for $2 \mathrm{~h}$. The beads were washed with $3 \times 50 \mu \mathrm{L}$ BSB buffer on a vacuum manifold (Millipore). An anti-EGFR antibody $(0.3 \mu \mathrm{g} / \mathrm{mL}, \mathrm{mAb} 11$, LabVision) was selected, and $30 \mu \mathrm{L}$ were added to each well. After an incubation of more than $60 \mathrm{~min}$, the beads were washed again as above. A secondary R-phycoerythrin-labeled antibody $(2.0 \mu \mathrm{g} / \mathrm{mL}$, goat anti-mouse, Dianova) with a volume of $30 \mu \mathrm{L} /$ well was incubated for $45 \mathrm{~min}$. Finally, the beads were washed, and a final volume of $75 \mu \mathrm{L}$ BSB was added to each well.

For competition experiments, soluble EGF (sEGF, Biomol) was mixed with the sample and coincubated with immobilized EGF-Biot-coupled beads. For detection, antiEGFR antibody mAb11 was applied at $1.25 \mu \mathrm{g} / \mathrm{mL}$ and the labeled anti-mouse antibody at $5.0 \mu \mathrm{g} / \mathrm{mL}$.

2.5. Readout and Data Analysis. A Luminex LX100 system (Luminex Corporation) was used to determine the beadbound reporter fluorescence. For each well, at least 100 events per bead ID were counted and the median fluorescence intensity (MFI) of the reporter dye was collected. Data was processed using $\mathrm{R}$, a language and environment for statistical computing and graphics [16]. For the comparison of two groups with differing EGFR expression values, a $P$ value was calculated with Student's $t$-test.

\section{Results}

In a first set of experiments, two concentrations of biotinylated EGF were immobilized onto beads, mixed, and applied to an assay with different amounts of total protein from cell lysates. For this study, BT-20 cells, known to express EGFR at level of $400 \mathrm{fmol} / \mathrm{mg}$ or $1.5 \times 10^{6}$ copies per cell [17], were chosen. For the subsequent detection of bead-bound EGFR, an anti-EGFR antibody was chosen that did not interfere with the EGF-EGFR interaction, according to the data sheet. No cross-reactivity between immobilized EGF-biotin, the anti-EGFR antibody, and the labeled anti-mouse detection antibody could be detected (data not shown). In Figure 1(a), it is shown that both the amount of lysate employed as well as the ligand density on the bead surface influenced the measured signal intensity and no saturation effects were observed for the tested lysate protein concentrations. EGF coupled to the beads at a concentration of $1.2 \mu \mathrm{M}$ showed increased signal intensities compared to the bead ID coupled with a $4 \mathrm{x}$ lower ligand concentration, in addition to a broader intensity range for the $1.2 \mu \mathrm{M}$ loaded EGF beads. As the utilized BT-20 cells are known to express higher levels of EGFR, a sample protein concentration of $500 \mu \mathrm{g} / \mathrm{mL}$, reflecting $15 \mu \mathrm{g}$ of total protein per well, was chosen for 


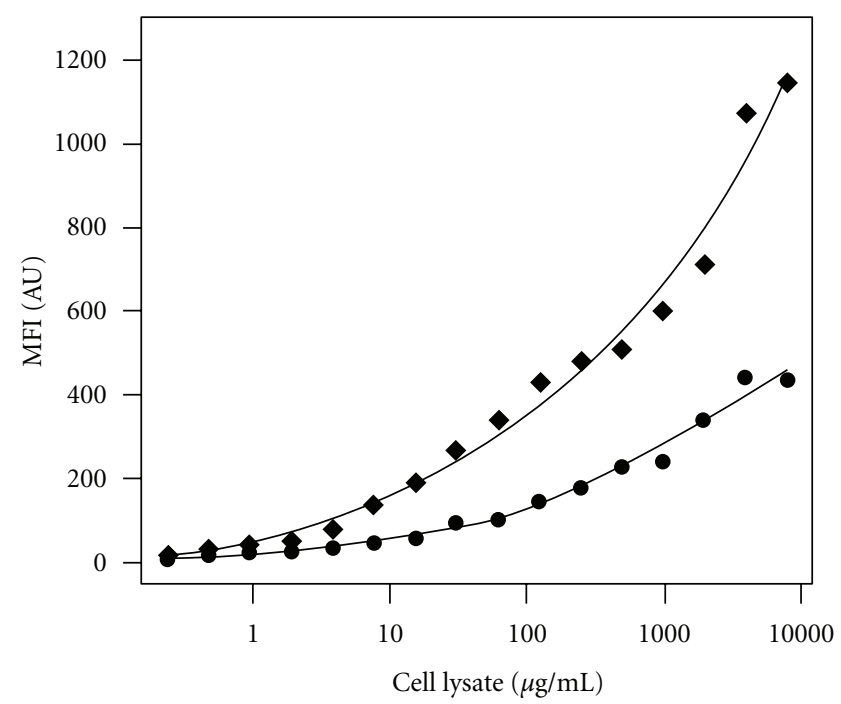

(a)

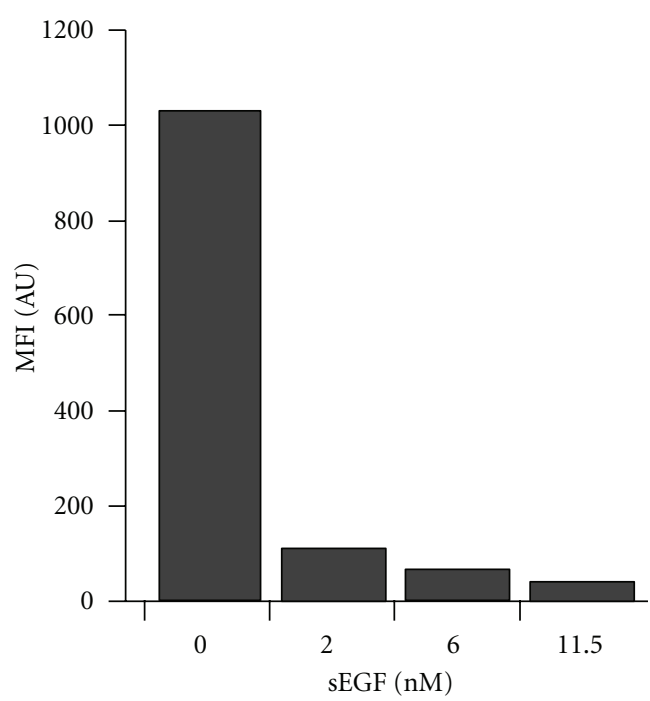

(b)

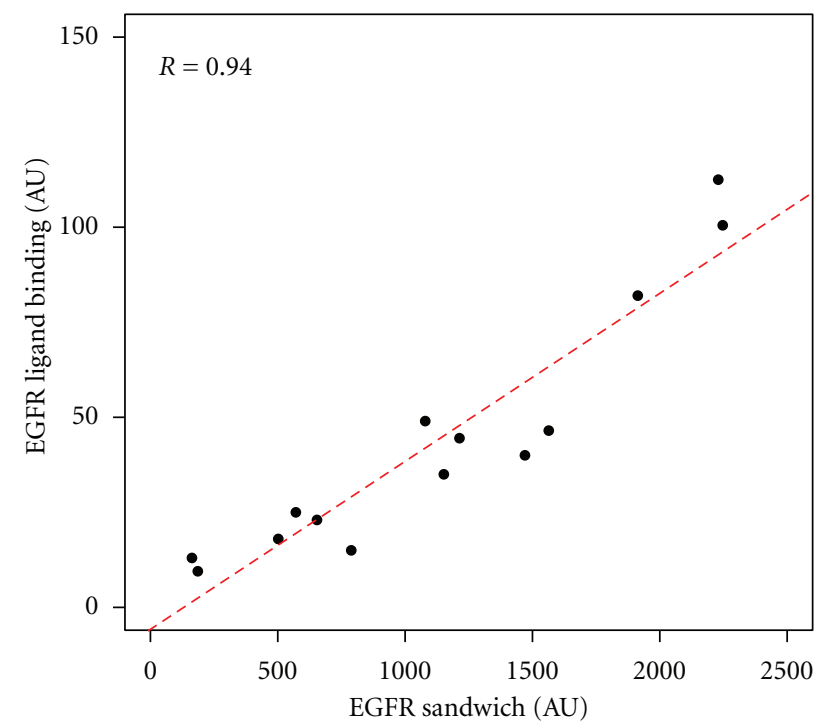

(c)

FIGURE 1: (a) Detection of EGFR in cell extracts. Beads coated with different concentrations of EGF were used to capture EGFR from a cell lysate in a concentration-dependent manner. The ligand EGF was immobilized at $1.2 \mu \mathrm{M}$ (diamonds) and $0.3 \mu \mathrm{M}$ (circles) on different bead types. Both bead sets were mixed and incubated with different amounts of BT-20 cell lysates. Captured EGFR was detected using an antiEGFR antibody and a labeled secondary antibody. (b) Specificity of capture activity. A BT-20 cell lysate $(500 \mu \mathrm{g} / \mathrm{mL})$ was coincubated with various concentrations of purified and unbiotinylated sEGF and beads coated with EGF-Biot (1.2 $\mu \mathrm{M})$. The amount of captured EGF receptor was strongly reduced at the presence of sEGF. This indicates that the bead-bound EGF-EGFR complex is captured in a specific fashion by applying an anti-EGFR antibody followed by a labeled secondary antibody. (c) Correlation of ligand binding and sandwich immunoassay. A series of tissue lysates with known EGFR concentrations were analyzed with both, a ligand binding assay and an immunoassay using an antibody as capture reagent. In both assays, the same anti-EGFR detection molecule was used and the profiles obtained reveal a correlation of 0.94 , which indicated a good concordance between the two tests.

the following studies to also facilitate the detection of EGFR in specimens with lower expression levels. To validate the specificity of the assay, meaning that EGF is capturing EGFR, BT-20 cell lysates were coincubated with nonbiotinylated soluble EGF (sEGF). In this competition assay, sEGF will bind to free EGFR binding sites and occupy them so that the immobilized EGF cannot bind to such a EGFR molecule. The results from this test (Figure 1(b)) showed a strong reduction in signal intensity at sEGF levels of $11.5 \mathrm{nM}(96 \%$ reduction) and $2 \mathrm{nM}$ (89\% reduction). This clearly indicated that the observed interactions are due to EGFR-EGF binding. Moreover, we also compared the ligand binding assay to a sandwich immunoassay with both tests being performed on beads and utilizing the same detection system. As shown in Figure 1(c), a concordance of $r=0.94$ was achieved for the profiles generated with breast cancer tissue samples 


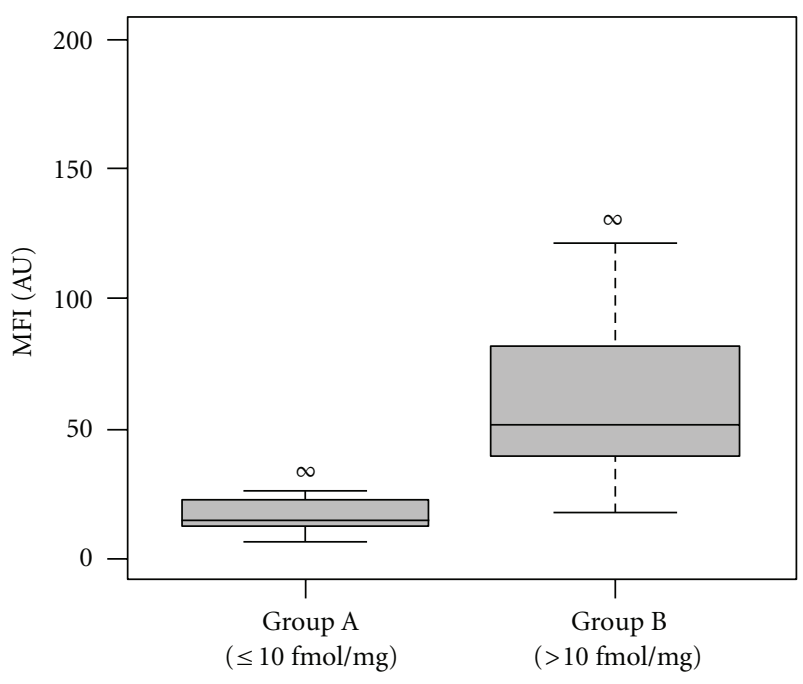

FIGURE 2: Analysis of breast cancer tissue samples. Forty-six breast cancer tissue samples originally analyzed for EGFR expression by a radio-ligand binding assay were reanalyzed in a bead-based ligand binding assay. A cut-off value of $10 \mathrm{fmol}$ EGFR per mg protein, determined by radio-ligand binding assay, was used to divide the samples into group A $(n=17)$ with EGFR values $\leq 10 \mathrm{fmol} / \mathrm{mg}$ and group B $(n=29)$ with EGFR values $>10 \mathrm{fmol} / \mathrm{mg}$. Samples were measured in a random order, and a $P$ value of $2.6 \mathrm{e}-11$ was calculated between the two groups.

(see below). This demonstrated that a protocol for a ligand binding assay was developed and that is allowed to provide specific and functional information for profiling the cell surface receptor EGFR in lysates.

Next, the EGFR ligand binding assay was applied in a proof-of-concept study to profile EGFR in 46 tumor samples derived from breast cancer patients. The tissue lysates were measured in random order at a total protein concentration of $0.5 \mathrm{mg} / \mathrm{mL}$ with the established protocol. The analyzed samples were grouped based on a clinically relevant cutoff level of $10 \mathrm{fmol} / \mathrm{mg}$ [5], which had been previously determined in radio-ligand binding experiments. As shown in Figure 2, 15 of 17 samples (88\%) from group A with EGFR $\leq 10 \mathrm{fmol} / \mathrm{mg}$ were measured with MFIs $\leq 25 \mathrm{AU}$, while samples with MFI $\geq 50$ AU were not affiliated to this group. For samples in group B with EGFR $>10 \mathrm{fmol} / \mathrm{mg}, 52 \%$ had MFI values $\geq 50 \mathrm{AU}$, and, for the remaining $48 \%$ with MFIs $\leq 50 \mathrm{AU}$, the highest EGFR value was $42 \mathrm{fmol} / \mathrm{mg}$. A sample containing $600 \mathrm{fmol} / \mathrm{mg}$ EGFR (not shown in Figure 2) was measured with an MFI $>1000$ AU thus served as a control. Between group A and $\mathrm{B}$, a $P$ value of $2.6 \mathrm{e}-11$ was calculated and demonstrated that the ligand binding assay performed well to provide complementary evidence for separating samples with high and low EGFR values.

\section{Discussion and Conclusion}

Miniaturized ligand binding assays, as described here for EGF and EGFR, offer a radiation-free tool to profile and study target molecules via their in vivo interaction partners compared to conventional radioimmunoassays or other antibody-based methods. In the presented approach, we investigate the potential of the immobilized receptor ligand EGF to capture EGFR in a miniaturized bead-based assay format in which EGF was immobilized to avidin-coated beads via an $\mathrm{N}$-terminal biotin modification. The chosen immobilization strategy enabled to maintain the binding properties of EGF and to achieve high signal intensities. Both, the EGF coupling concentration as well as the amount of the applied sample affected signal intensities. As described elsewhere, the extracellular domain of EGFR undergoes a conformational change upon ligand binding on the cell surface [7] and it seemed likely that such changes should occur even when EGFR is being bound by an immobilized capture ligand. Even though EGF-EGFR interactions take place with a free EGF binding to anchored or soluble EGFR in vivo, attaching EGF to a solid support did not hinder the two proteins from binding to each other.

In competition assays, it was revealed that the binding by detected immobilized EGF was affected by purified and soluble sEGF, thus confirming that the measured interactions were from EGF and EGFR. The strong inhibitory effect of soluble EGF is likely to reflect advantages in conformation adaptation of EGFR when binding in solution. Compared with purely antibody-based sandwich immunoassays, that were described earlier [18], the influence of conformational may have a greater influence on the ligand binding assay. This could be interpreted from the decreased intensity level that was found in ligand binding assays. In addition, this observation may eventually be a consequence of the fact that the total number of receptors accessible to ligand binding is lower due to the applied extraction procedure and sample storage, which may not keep all receptors in nondenatured and functional states.

To investigate the possible potential applicability of this approach in future clinical sample analysis, EGFRcharacterized tumor samples from breast cancer patients were studied. The analyzed samples were grouped based on a clinically relevant cut-off level for EGFR, and it was possible to discriminate samples with expression levels below or above cutoff using the described assay setup. Even though this small proof-of-concept study may suggest that such miniaturized ligand binding approaches could have the potential to be a supplementary alternative to radioactivitybased tests, further testing and assay evaluations need to be performed.

The demonstrated miniaturization of receptor ligand binding assays allowed an analysis of potentially functional receptors from minimal sample amounts and would decrease costs by reducing the amount of material and reagents needed. The reduction of sample volume would be of particular importance for applications where only minimal amounts of specimen are available, such as the analysis of multiple tumor markers from biopsies. In addition, the miniaturized ligand binding assays may have the capability to supplement existing single- or multiplexed sandwich immunoassays to further increase the evidence for specific target presence and to add informatory value. 
In conclusion, the ligand binding assay system demonstrates that ligand receptor-binding assays can be miniaturized and offer to become part of the variety of protein microarray-based approaches performed today. With new proteins and pathways emerging as indicators of disease, the procedure presented here describes a possibility to profile the interactions of proteins, such as cell surface receptors, in a miniaturized assay. It is possible that such assays are of value for variety of assays in the fields of proteomics and diagnostics.

\section{Abbreviations}

EGFR: Epidermal growth factor receptor

EGR: $\quad$ Epidermal growth factor

EGF-Biot: Biotinylated EGF

sEGF: $\quad$ Soluble EGF

MFI: $\quad$ Median fluorescence intensity.

\section{Acknowledgments}

The authors would like to thank Jutta Bachmann for careful reading of this paper. Funding of the project was provided by the Government of Baden-Württemberg through Grant "Adressierbare BioChip arrays für die Diagnostik und Medizin" (no. 720.430-21/15).

\section{References}

[1] R. S. Yalow and S. A. Berson, "Immunoassay of endogenous plasma insulin in man," The Journal of Clinical Investigation, vol. 39, pp. 1157-1175, 1960.

[2] B. Ayoglu, A. Häggmark, M. Neiman et al., "Systematic antibody and antigen-based proteomic profiling with microarrays," Expert Review of Molecular Diagnostics, vol. 11, no. 2, pp. 219-234, 2011.

[3] M. F. Templin, D. Stoll, J. M. Schwenk, O. Pötz, S. Kramer, and T. O. Joos, "Protein microarrays: promising tools for proteomic research," Proteomics, vol. 3, no. 11, pp. 2155-2166, 2003.

[4] J. G. M. Klijn, P. M. J. J. Berns, P. I. M. Schmitz, and J. A. Foekens, "The clinical significance of epidermal growth factor receptor (EGF-R) in human breast cancer: a review on 5232 patients," Endocrine Reviews, vol. 13, no. 1, pp. 3-17, 1992.

[5] S. Nicholson, J. R. C. Sainsbury, G. K. Needham, P. Chambers, J. R. Farndon, and A. L. Harris, "Quantitative assays of epidermal growth factor receptor in human breast cancer: cut-off points of clinical relevance," International Journal of Cancer, vol. 42, no. 1, pp. 36-41, 1988.

[6] S. R. Hubbard and J. H. Till, "Protein tyrosine kinase structure and function," Annual Review of Biochemistry, vol. 69, pp. 373398, 2000.

[7] A. W. Burgess, H. S. Cho, C. Eigenbrot et al., "An open-andshut case? recent insights into the activation of EGF/ErbB receptors," Molecular Cell, vol. 12, no. 3, pp. 541-552, 2003.

[8] C. L. Arteaga, "Overview of epidermal growth factor receptor biology and its role as a therapeutic target in human neoplasia," Seminars in Oncology, vol. 29, no. 5, supplement 14, pp. 3-9, 2002.
[9] A. A. Jungbluth, E. Stockert, H. J. S. Huang et al., "A monoclonal antibody recognizing human cancers with amplification/overexpression of the human epidermal growth factor receptor," Proceedings of the National Academy of Sciences of the United States of America, vol. 100, no. 2, pp. 639-644, 2003.

[10] M. V. Grandal and I. H. Madshus, "Epidermal growth factor receptor and cancer: control of oncogenic signalling by endocytosis," Journal of Cellular and Molecular Medicine, vol. 12, no. 5A, pp. 1527-1534, 2008.

[11] D. A. Eberhard, G. Giaccone, and B. E. Johnson, "Biomarkers of response to epidermal growth factor receptor inhibitors in non-small-cell lung cancer working group: standardization for use in the clinical trial setting," Journal of Clinical Oncology, vol. 26, no. 6, pp. 983-994, 2008.

[12] A. M. Valentini, M. Pirrelli, and M. L. Caruso, "EGFR-targeted therapy in colorectal cancer: does immunohistochemistry deserve a role in predicting the response to cetuximab?" Current Opinion in Molecular Therapeutics, vol. 10, no. 2, pp. 124-131, 2008.

[13] C. M. Stoscheck, "Enzyme-linked immunosorbent assay for the epidermal growth factor receptor," Journal of Cellular Biochemistry, vol. 43, no. 3, pp. 229-241, 1990.

[14] R. Zeillinger, F. Kury, P. Speiser, G. Sliutz, K. Czerwenka, and E. Kubista, "EGF-R and steroid receptors in breast cancer: a comparison with tumor grading, tumor size, lymph node involvement, and age," Clinical Biochemistry, vol. 26, no. 3, pp. 221-227, 1993.

[15] A. Ullrich and J. Schlessinger, "Signal transduction by receptors with tyrosine kinase activity," Cell, vol. 61, no. 2, pp. 203212,1990

[16] R. Ihaka and R. Gentleman, "R: a language for data analysis and graphics," Journal of Computational and Graphical Statistics, vol. 5, no. 3, pp. 299-314, 1996.

[17] I. Brotherick, T. W. J. Lennard, S. E. Wilkinson, S. Cook, B. Angus, and B. K. Shenton, "Flow cytometric method for the measurement of epidermal growth factor receptor and comparison with the radio-ligand binding assay," Cytometry, vol. 16, no. 3, pp. 262-269, 1994.

[18] N. Schneiderhan-Marra, A. Kirn, A. Döttinger et al., "Protein microarrays-a promising tool for cancer diagnosis," Cancer Genomics and Proteomics, vol. 2, no. 1, pp. 37-42, 2005. 

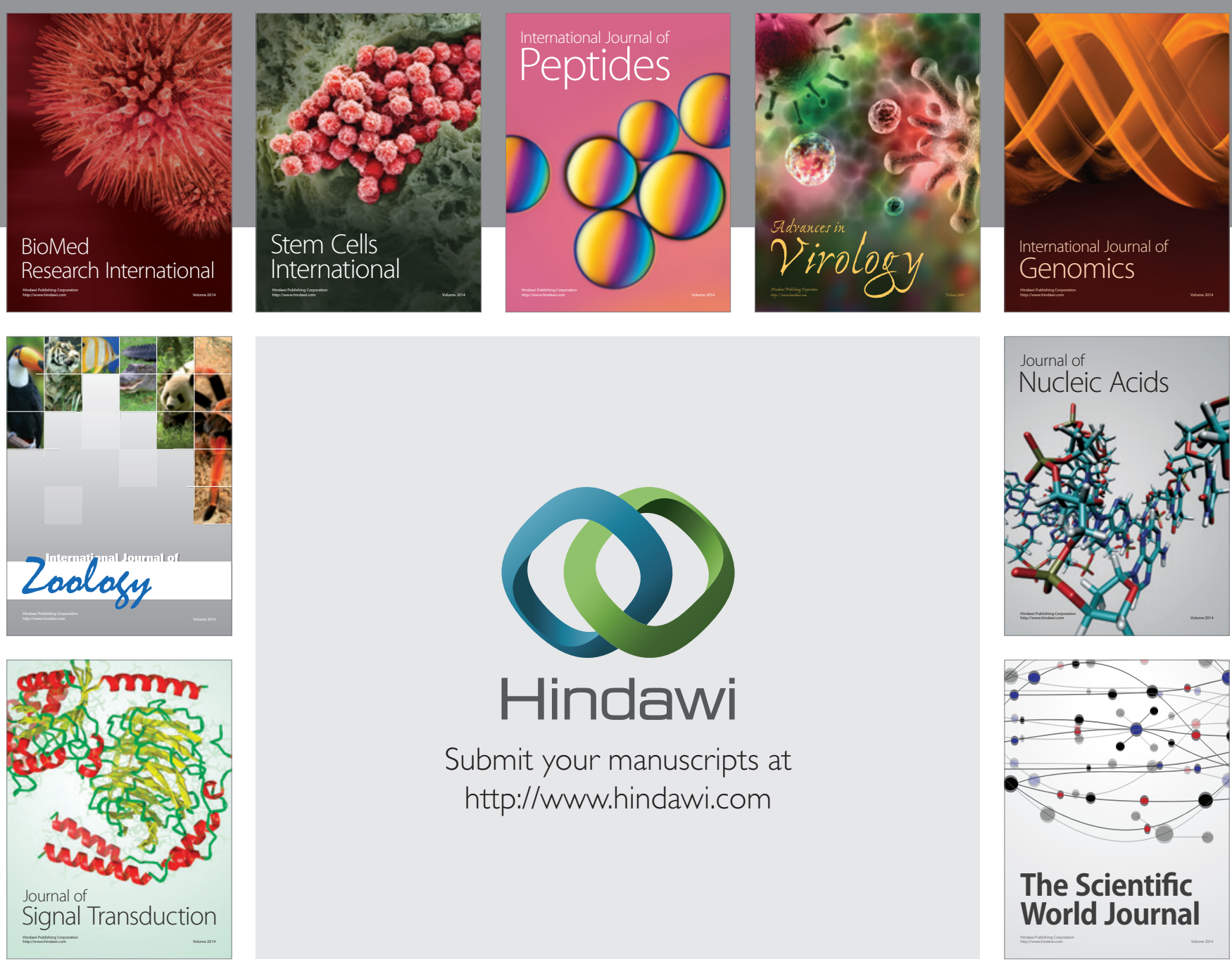

Submit your manuscripts at

http://www.hindawi.com
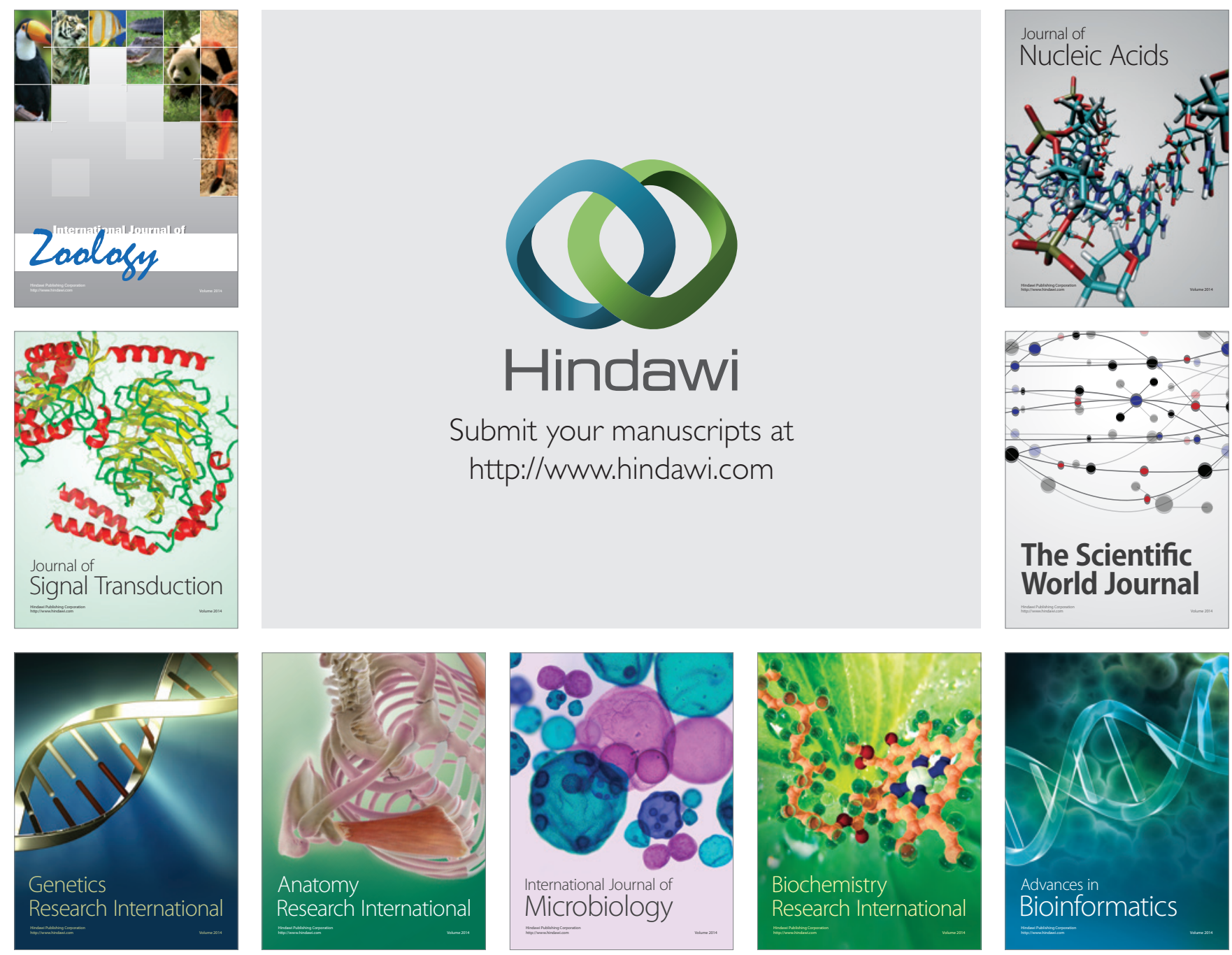

The Scientific World Journal
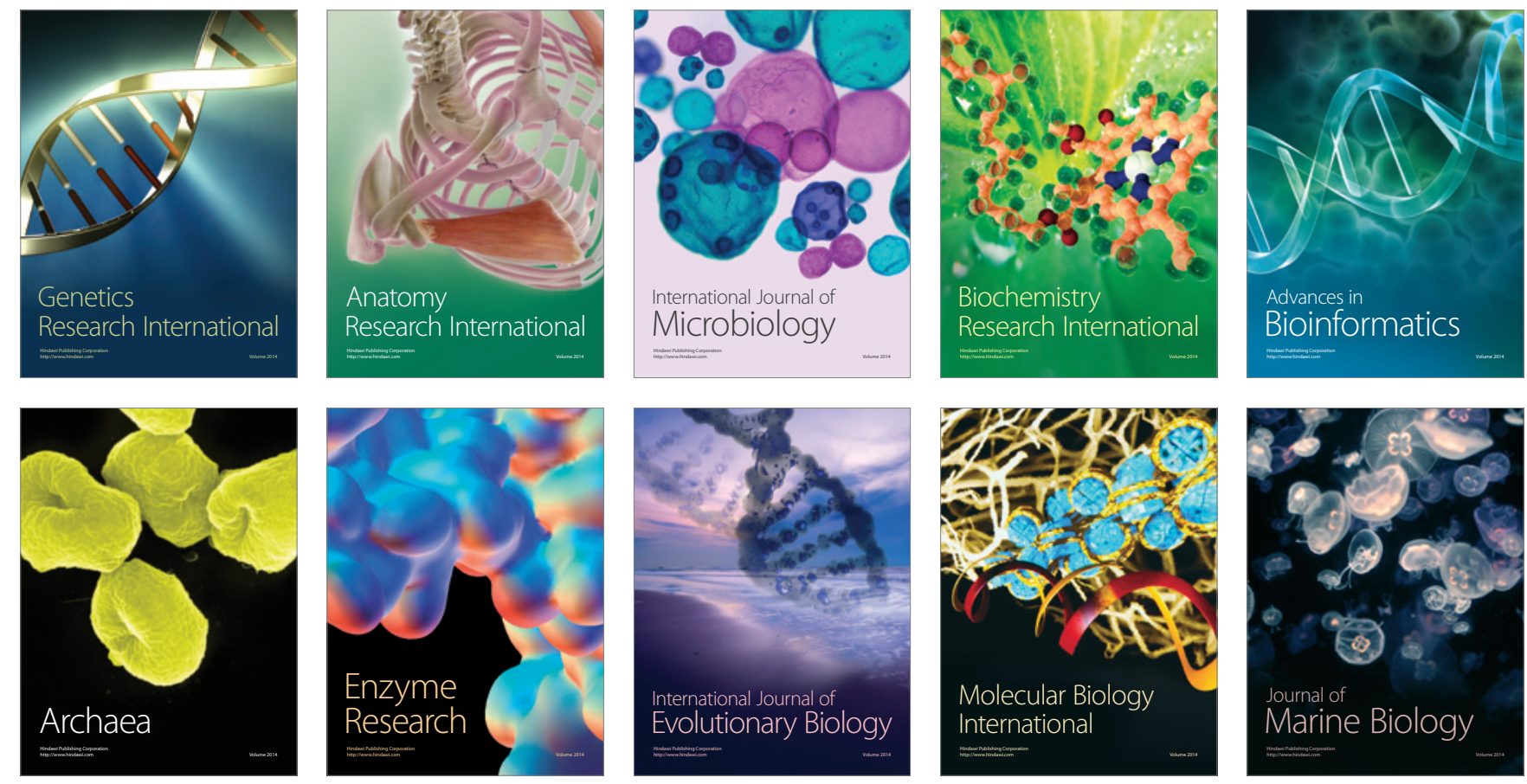